Military Technical College Kobry Elkobbah, Cairo,

Egypt.

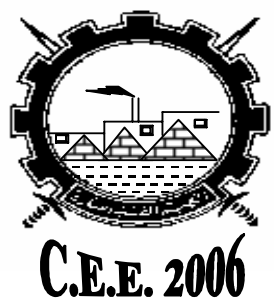

$3^{\text {rd }}$ International Conference

On

Chemical \& Environmental

Engineering

\title{
MECHANICAL AND MICRO-STRUCTURAL CHARACTERISTICS OF POLYMERIMPREGNATED CEMENT MORTAR COMPOSITES
}

\author{
ABO-EI-Enein S. A. ", EL-Safty M. M. *, Sadek M. A. **, \\ Younes M. M. ${ }^{* *}$ and Zohdy K. M.
}

\begin{abstract}
Hardened ordinary Portland cement mortar pastes were prepared with different water / cement ratios within the range of 0.25 to 0.50 and cured for various time intervals up 28 days. At each hydration time the hardened specimens were, then, impregnated with different monomers; these are : castor oil (C.O), isocyanate and methyl methacrylate (MMA). Polymerization was carried out by subjecting the impregnated samples to different doses of $\gamma$-radiation where polyurethane (PU), polyurethane-methyl methacrylate copolymer were formed within the pore system. The influence of polymer impregnation of the various physico-mechanical characteristics of the resulting composites, namely, compressive strength, of the samples in connection with water cement ratio, radiation dose and curing period was discussed. Scanning electron microscopy (SEM) was employed to study the microstructural characteristics of the neat hardened OPC mortar pastes and their polymer-impregnated composites.
\end{abstract}

\section{KEY WORDS}

Ordinary Portland cement (OPC), polyurethane (PU), castor oil (C.O.), methyl methacrylate (MMA)

* Faculty of Science, Ain Shams University.

** Higher Technological Institute, $10^{\text {th }}$ of Ramadan, Egypt. 


\section{INTRODUCTION}

Increased industrial interest has been arisen all over the world in the polymer impregnation technique for enhancing the properties of concrete [1]. Polymerimpregnated concrete is a conventional concrete made with Portland cement, wet cured, dried and subsequently impregnated with liquid monomer and polymerized by gamma radiation or by thermal treatment. The associated effects of such application have significantly improved the material's quality. Typical improvements of these properties include compressive strength, modulus of elasticity, modulus of rupture, flexural modulus and hardness impact values in addition to the tremendous decrease in water absorption. Various studies cover the factors affecting production and durability and show a remarkable improvement in mechanical properties [2-5]. Other indicates that polymer impregnation improves the properties of concrete [6-11].

The main objectives of this investigation are to study the main characteristics of polymer impregnate cement mortar composites to improve their mechanical properties with increased durability.

\section{EXPERIMENTAL}

The materials used in this investigation were ordinary Portland cement (OPC), standard sand, castor oil (C.O.), 4, 4'-diphenylmethane diisocyanate (MDI) and methyl methacrylate (MMA).

A freshly produced sample of (OPC) was supplied by the National Cement Company (NCC). Its oxide composition is given as: $\mathrm{SiO}_{2},(29.93) ; \mathrm{Al}_{2} \mathrm{O}_{3},(5.13) ; \mathrm{Fe}_{2} \mathrm{O}_{3},(4.17)$; $\mathrm{CaO},(63.81) ; \mathrm{MgO},(2.25) ; \mathrm{SO}_{3},(1.75)$; insoluble residue, (0.69) and ignition loss, (1.73). The specific surface area of this cement was $3260 \mathrm{~cm}^{2} / \mathrm{g}$.

A sample of sand with a standard grain size was used in the present investigation.

The specifications of the castor oil (C.O.) sample used in this investigation were summarized as follow: acid value $2.0 \mathrm{max}, \%$ moisture \& volatile 0.02 max, equivalent weight 342 , hydroxyl value $160-168$, iodine value $83-88$, saponification value $175-185$ and viscosity at $25^{\circ} \mathrm{C}$ is $6.3-8.9$.

A sample of 4, 4'-diphenylmethane diisocyanate (MDI), isomers under the name of VORACOR CD 526 ISOCYANATE, Dow Company, was used. It has the following characteristics: viscous liquid, dark amber, slightly musty, density $=1.22 \mathrm{~g} / \mathrm{cm}^{3}$ at $25^{\circ} \mathrm{C}$ and NCO content of $31 \%$ (ASTM D 5155).

Methyl methacrylate is one of the few monomers which can be made to yield highmolecular weight polymer by all known methods of initiation. A sample of BDH grade MMA was used in a liquid form having a density of $0.940 \mathrm{gm} / \mathrm{cm}^{3}$, and contains quinol as a stabilizer. When polymerized, it gives a stable polymer at room temperature.

Hardened OPC mortar pastes of various porosity, having different initial water/cement $(\mathrm{W} / \mathrm{C})$ ratios of $0.25,0.30,0.40$ and 0.50 by weight, were prepared by mixing the required amount of cement with standard sand using water to form mortar pastes. This was deliberately carried out in order to get cement mortar pastes having varying ranges of porosity. 
Before impregnation, the hardened specimens were immersed in methanol-acetone mixture (1: 1 volume ratio) for about 1 hour to stop the hydration process; this is followed by drying in an electric oven at $100 \pm 5^{\circ} \mathrm{C}$ for 24 hours. The dried specimens were then placed into a desiccator until the time of the impregnation process.

The dried specimens of the hardened cement mortar pastes representing each mix were impregnated by either a mixture of castor oil and 4, 4'-diphenylmethane diisocyanate (to obtain polyurethane) or a mixture of castor oil, 4, 4'diphenylmethane diisocyanate and methyl methacrylate (to obtain polyurethanemethyl methacrylate (PU/MMA) copolymer). The monomer impregnated specimens were then irradiated using various doses of $\mathrm{Y}$-rays required for the polymerization process within the pore system of the resulting composites.

The various neat and polymer impregnated cement mortar pastes were tested for their compressive strength and microstructure using the scanning electron microscope (SEM) by the methods described previously in earlier investigations [ $12-14]$.

\section{RESULTS AND DISCUSSION}

\section{Characteristics of OPC mortar pastes:}

\subsection{Compressive Strength}

The compressive strength values obtained for all of the hardened mortar pastes investigated are graphically represented as a function of curing time in Fig. (1) for the mortar pastes made with different water/cement ratios.

It is clear from Fig.(1) that the compressive strength of the various hardened cement mortar paste increases with the increase of the time of hydration as well as the decrease of water/cement (W/C ) ratio. The results of Fig. (1) show that the compressive strength values decrease sharply with the increase of water/cement ratio of the hardened mortar paste. The strength of the hardened mortar paste is usually correlated with the degree of hydration and total porosity. The strength resides in the solid material of the mortar pastes, and both the volume and weight of the solids increase with increasing degree of hydration; i.e. increase of curing age. The pores, naturally, reduce the compressive strength values. With progressing hydration, the total porosity decreases, because the hydration products occupy a greater volume than the unhydrated cement; consequently a part of the hydration products deposit in the pores. Thus, the two effects work in the same direction; with increasing degree of hydration more cementing and strength producing material is formed, and at the same time the porosity also decreases. The compressive strength results presented here in this investigation show good correlations with both degree of hydration and total porosity. Therefore, the degree of hydration and the total porosity of the hardened mortar paste represent the two main factors affecting the developed strength. These two factors are not the only ones, and some other factors might play a certain role in affecting the compressive strength results; one of these factors is probably related to the pore structure of the hardened mortar paste. 
Recent studies indicate that the wide pores affect the compressive strength more than microspores [15-16]. The strength is reduced markedly in presence of higher fraction of wide pores in the mortar paste; while micro pores, have a smaller effect on the reduction of compressive strength. Evidently, the hardened mortar pastes made with low porosities (low initial W/C ratios) possess higher strength values as compared with the mortar pastes made with higher W/C ratios. Therefore, low porosity mortar pastes are denser than high porosity mortar pastes. These results indicate that the porosity of the hardened mortar pastes plays the dominant factor affecting the compressive strength rather than the degree of hydration.

\section{Characteristics of OPC - polyurethane impregnated mortar composites.}

\subsection{Compressive Strength}

The most important observation in the cement-polymer system is that, there is a significant increase in the compressive strength of the resulting cement - polymer composites over that of neat cement paste. The present investigation was carried out in order to study the dependence of the compressive strength of polymer impregnated OPC mortar pastes on the type of PU used, and the W/C ratio. The effect of polyurethane ( castor oil and diisocyanate monomers on the compressive strength of OPC mortar pastes made with different W/C ratios and hardened for periods of various curing $1,3,7$ and 28 days will be discussed.

The variation of the compressive strength of polymer impregnated OPC mortar pastes made with different initial porosities (W/C ratios) at various hydration ages are graphically represented in Fig. (2). Fig. (2) Showed that the compressive strength obtained for all of the hardened polymer impregnated mortar composites seems to be a function of the initial porosity of the un-impregnated mortar paste. The amount of polymer formed will reduce the total porosity as a result of filling of the residual pore system of the hardened OPC mortar pastes and therefore, the compressive strength of resulting composites will be increased. Therefor, the polyurethane formed in the residual pore spaces of the impregnated cement OPC mortar composites leads to a noticeable improvement in the compressive strength of the resulting composites.

The results of Fig. (3) indicate that for the mortar pastes made with low initial porosities (W/C ratios of $0.25 \& 0.30$ ) the compressive strength values of polymer impregnated low porosity OPC mortar pastes are markedly higher than those of the ( un-impregnated mortar pastes). This increase in the strength values was more obvious during the early hydration ages ( $1-7$ days). At longer ages of hydration, the improvement of the strength becomes less pronounced.

For low porosity mortar pastes, made with the initial W/C ratio of 0.25 and 0.30 , the curing of the polymer within their limited pore spaces was almost complete by using lower radiation doses $(0.5$ - 1Mrad). With increasing initial porosity of the mortar pastes (W/C 0.40 and 0.50 ), the radiation dose required for the complete curing of the polymer increases.

Evidently, the results of Figs. (3), obtained for the mortar pastes made with W/C ratios of 0.40 and 0.50 , indicated that the improvements in the compressive strength 
values of the polymer impregnated mortar pastes at the later ages mortar pastes were less than those obtained at the early hydration ages.

In general, it can be concluded that the initial porosity of the hardened OPC mortar pastes (as controlled by the initial W/C ratio) before impregnation is one of the main factors affecting the compressive strength of the polymer impregnated OPC mortar composites. This can be seen from the differences of the compressive strength values of the hardened OPC mortar pastes made with different initial porosities. The improvement in compressive strength values as a result of polymer impregnation is highly distinguished for the low porosity OPC mortar pastes as compared to such strength improvement for the mortar pastes made with higher initial porosity.

Obviously, for all of the hardened mortar pastes, the strength improvement is more noticeable for the resulting OPC mortar composites at the early hydration ages. This is related to the fact that the total porosity of each hardened mortar paste at the early ages of hydration before and after impregnation, is higher than at later ages as hydration proceeds, larger amounts of cement hydrates are deposited with the pore spaces of the hardened mortar pastes leading to a reduction of the total pore system, this leads to a decrease in the extent of polymer loading of the resulting composite on prolonged hydration of the hardened OPC mortar pastes. Therefor, the change in the total porosity affects the amount of impregnated monomers diffusing into the pore system of the specimens, and consequently affecting the amount of polyurethane formed during polymerization within the pores of the hardened OPC mortar pastes.

\subsection{SEM micrographs}

The microstructure of the hardened OPC mortars obtained after 28 days of hydration indicated that the formed hydrates are engulfed by the polymer formed within the residual pore system of the hardened mortar pastes as shown in Fig. (3).

The SEM Micrographs of the hardened OPC mortar paste made with the lower initial porosity $(\mathrm{W} / \mathrm{C}=0.25)$ and cured for 28 days after impregnation with polyurethane and irradiated by $0.5 \mathrm{Mrad}$, indicated that the interlocking fibers of calsium silicate hydrate $(\mathrm{CSH})$ as well as rod-like crystals of calcium sulphoaluminate hydrates and the hexagonal crystals of $\mathrm{Ca}(\mathrm{OH})_{2}$, are almost embedded within the polymer formed in the residual pores of the hardened mortar pastes as shown in Fig.(3).

Scanning electron microscopic (SEM) examination of the hardened OPC mortar paste made with W/C ratio of 0.40 after 28 days of hydration after impregnation with polyurethane and irradiated by $0.5 \mathrm{Mrad}$, indicated the almost coating of the formed hydration products as a result of polymer impregnation Fig.(3). 


\section{Characteristics Of Opc - (Polyurethane - Methyl Methacrylate ) Copolymer Impregnated Mortar Composites:}

\subsection{Compressive strength}

The most important characteristics of the cement-polymer system is that, there is a significant increase in the compressive strength of the resulting cement-polymer composites over that of neat cement paste. The present investigation was carried out in order to study the dependence of the compressive strength of polymer impregnated - OPC mortar pastes on the origin of polyurethane used as well as the initial W/C ratio of the hardened mortar pastes. The effect of the copolymer of made polyurethane ( castor oil and diisocyanate) and methyl methacrylate (MMA) monomers on the compressive strength of OPC mortar pastes, made with different initial W/C ratios and hardened for various curing periods of $1,3,7$, and 28 days, will be discussed.

The variations of the compressive strength of the resulting copolymer impregnated OPC mortar pastes, made with different initial porosities (W/C ratios) at various hydration ages, and are graphically represented in Fig. (4). The results of Fig. (4) showed that the compressive strength obtained for all of the hardened polymer impregnated mortar composites seems to be a function of the initial porosity of the un-impregnated mortar pastes. In this case the amount of copolymer formed will reduce the total porosity as a result of filling of the residual pore system of the hardened OPC mortar pastes and therefore, the compressive strength values of resulting composites will be increased over those of the hardened OPC mortar pastes impregnated with polyurethane polymer. Therefore, the copolymer formed in the residual pore spaces of the impregnated OPC cement mortar composites leads to a noticeable improvement in the compressive strength of the resulting composites as compared with the strength values obtained for polyurethane - impregnated mortar composites.

The results of Fig. (4) indicate that for the mortar pastes made with low initial porosities (W/C ratios of $0.25 \& 0.30$ ), the compressive strength values of the copolymer impregnated low porosity OPC mortar pastes are markedly higher than those of the un-impregnated mortar pastes and those impregnated with polyurethane polymer. This increase in the strength values is more obvious during the early hydration ages ( $1-7$ days). At longer ages of hydration, the improvement of the strength becomes less pronounced.

For low porosity mortar pastes, made with the initial W/C ratio of 0.25 and 0.30 , the curing of the copolymer within their limited pore spaces is almost complete by using relatively lower radiation doses. With increasing initial porosity of the mortar pastes (W/C 0.40 and 0.50 ), the radiation dose required for the complete curing of the copolymer increases.

Evidently, the results of Fig. (4), obtained for the mortar pastes made with W/C ratios of 0.40 and 0.50 , indicated that the improvements in the compressive strength values of the copolymer impregnated mortar pastes at the later ages mortar pastes are less than those obtained at the early hydration ages; this result is related to the 
accumulation of cement hydrates within the pore system of mortar pastes at longer curing ages.

In general, it can be concluded that the initial porosity of the hardened OPC mortar pastes (as controlled by the initial W/C ratio) before impregnation is one of the main factors affecting the compressive strength of the resulting polymer impregnated OPC mortar composites. This can be seen from the differences of the compressive strength values of the hardened OPC mortar pastes made with different initial porosities.

Obviously, for all of the hardened mortar pastes, the strength improvement is more noticeable for the resulting OPC mortar composites at the early hydration ages. This is related to the fact that the total porosity of each hardened mortar paste at the early ages of hydration before and after impregnation, is higher than that at later ages. As hydration proceeds, larger amounts of cement hydrates are deposited within the pore spaces of the hardened mortar pastes leading to a reduction of the total pore system; this leads to a decrease in the extent of copolymer loading of the resulting composite on prolonged hydration of the hardened OPC mortar pastes. Therefore, the change in the total porosity affects the amount of impregnated monomers diffusing into the pore system of the specimens, and consequently affecting the amount of copolymer of polyurethane and polymethyl methacrylate formed during polymerization within the pores of the hardened OPC mortar pastes.

\subsection{SEM micrographs}

The microstructure of the hardened OPC mortars obtained after 28 days of hydration followed by impregnation with polyurethane ( castor oil \& 4, 4'-diphenylmethane diisocyanate) - methyl methacrylate (MMA) copolymer showed an almost the same morphology of the hardened neat OPC paste; i.e. the formed hydrates retain their morphology after impregnation.

The SEM Micrographs of the hardened OPC mortar paste made with the lower initial porosity $(\mathrm{W} / \mathrm{C}=0.25)$ and cured for 28 days, indicated a sort of carbonation fibers of $\mathrm{CSH}$ as well as rod-like crystals of calcium sulphoaluminate hydrates (ettringite, $\mathrm{C}_{3} \mathrm{~A} .3 \mathrm{CaSO}_{4} .32 \mathrm{H}_{2} \mathrm{O}$ ) as shown in Fig. (5). The hexagonal crystals of $\mathrm{Ca}(\mathrm{OH})_{2}$ (portlandite) are also indicated in the micrographs.

Scanning electron microscopic (SEM) examination of the hardened OPC mortar paste made with W/C ratio of 0.40 after 28 days of hydration, indicated that the formed micro-crystalline and long (thin) fibrous particles of calcium silicate hydrates $(\mathrm{CSH})$ as well as crystalline $\mathrm{Ca}(\mathrm{OH})_{2}$ are still appeared after impregnation with polyurethane-MMA copolymer as shown in Fig.(5). 


\section{REFRENCES}

[1] Dessouki, A.M.; Ismail, M.R.; El-Hemaly, S.A.S. and Abo-El-Enein, S. A., "Compressive Strength of Radiation-Induced Polymer Impregnated Autoclaved, Lime-Rich Clay", Radiation Physics and Chemistry, (27),437-442(1986).

[2] Abo-El-Enein, S. A., El-Hemely, S.A., El Miligy, A. A. \& Zaidan, M. R., "Polymer impregnation of Hardened Cement Pastes of Various Porosities". In Polymers in Concrete, $3^{\text {rd }}$ Intern. Cong. on Polymers in Concrete, 729-41(1981).

[3] Auskern, A. \& Horn, W., Some properties of polymer impregnated cements and concretes. Journal of the American Ceramic Society, (54),282-5,(1971)

[4] Cheng-Hsin Chen, R. Huang, J.K. Wu and Chien-Hung Chen "Influence of soaking and polymerization conditions on the properties of polymer concrete", Construction and Building Materials, In Press, Corrected Proof, Available online 21 March (2005).

[5] Dikeou, J. T., Review of worldwide developments and use of polymers in concrete. In Proc. of the Ist Intern. Cong. On Polymer Concretes. The Concrete Soc., UK, The Construction Press, 2-8,(1975).

[6] Dikeou, J.T., Steinberg, M., Backstrom, J. E. \& Kukachka, L. E., Polymerization makes tougher concrete. ACl Journal Proceedings, 66(10), 829-39, (1969).

[7] Dong Zhang, Jianming Zhou, Keru Wu and Zongjin Li, "Granular phase changing composites for thermal energy storage" Solar Energy, 78(3), 471-480 (2005).

[8] Chen, J.J.; Zampini, D. and Walliser, A." High-pressure epoxy-impregnated cementitous materials for microstructure characterization" Cement and concrete Research, (32)1, 1-7 (2002).

[9] Nagaraj, T.S. \& Sundara Raja lyengar, K.T., Strengthening of damaged concrete by in situ polymerization. In Polymers in Concrete, $3^{\text {rd }}$ Intern. Cong. on Plymers in Concrete, May, 1981.

[10] Rauf, M.A. and McNeill, I.C.,"Thermal degradation of gamma irradiated polymers polymethylmethacrylate", Polymer Degradation and stability, (40)2,263-266, [1993].

[11] El-Hemaly, S.A.S.; El-Didamony, H. ; Abo-El-Enein, S. A. and El-Farouk, O. "The Influence of Autoclaving Conditions on Some Physicochemical Properties of Cellular Concrete I-Silica-Lime System", $1^{\text {st }}$ Inter. Confer. Appl. Sci., Vol. IV, Zagazig Univ., Zagazig, 30, 1207-1221(1985).

[12] El-Hemaly, S.A.S.; Abo-El-Enein, S. A.; El-Miligy, A.A. and Zaidan, M.R. "Radiation-Chemical Treatment of Cement Polymer Composites, I-Bulk Density", TIZ (Tonindustrie Zeitung), (105)1, 31-33(1981).

[13] Yoshihiko Ohama "Recent progress in concrete-polymer composites" Advanced Cement Based Materials, 5(2), 31-40, [1997].

[14] Yoshihiko Ohama "Recent progress in concrete-polymer composites" Advanced Cement Based Materials, (5)2, 31-40 (1997).

[15] Mikhail, R.Sh.; Abo-El-Enein, S. A., Abd-El-Khalik and Gahr, N.A. "Autoclaved Slag-Clinker-Sand Pastes : Surface Area, Pore structure and Compressive Strength", Cement and Concrete Research, ․․ pp. 77-86 (1978).

[16] Abo-El-Enein, S. A.; Mikhail, R.Sh.; Daimon,M. and Kondo, R. "Surface Area and Pore Structure of Hydro Thermal Reaction Products of Granulated Blast furnace Slage", Cement and Concrete Research, ․․ pp. 151-160 (1978). 


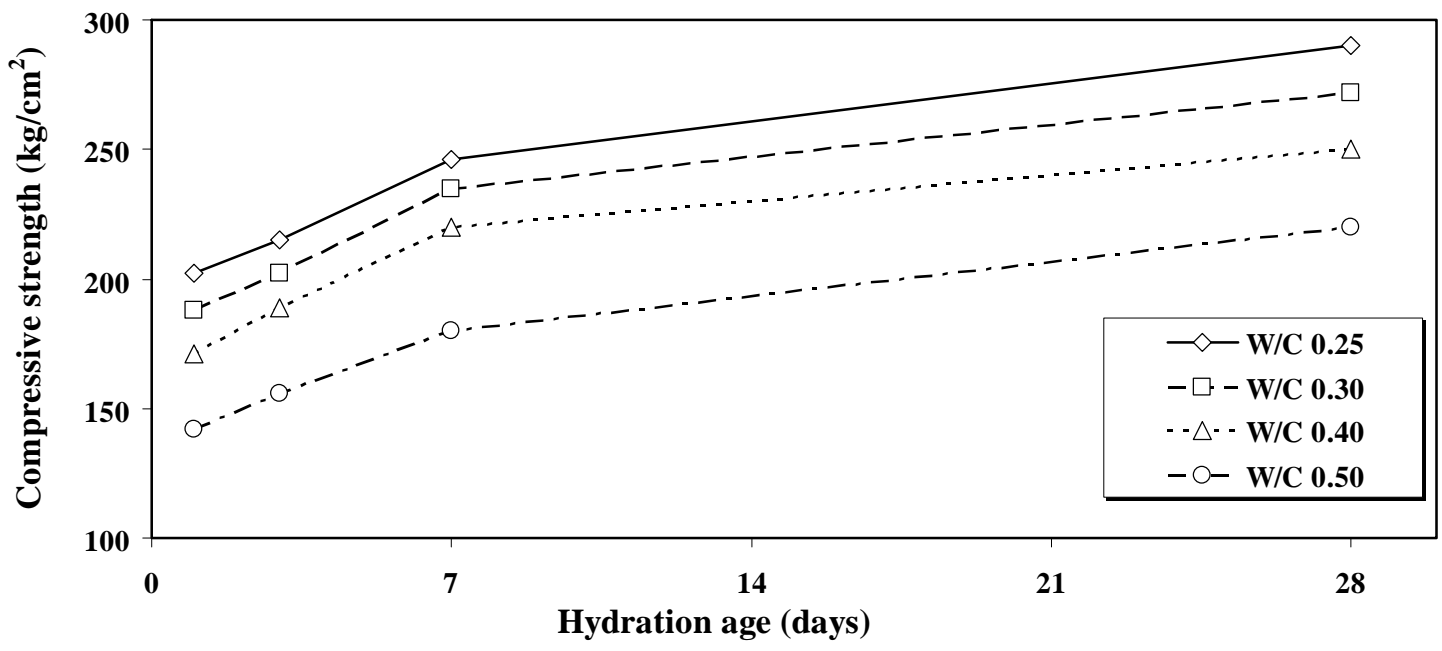

Fig. (1): Compressive strength $(\mathrm{kg} / \mathrm{cm} 2)$ of the hardened neat OPC mortar pastes made by using different W/C ratios (blank) versus age of hydration.
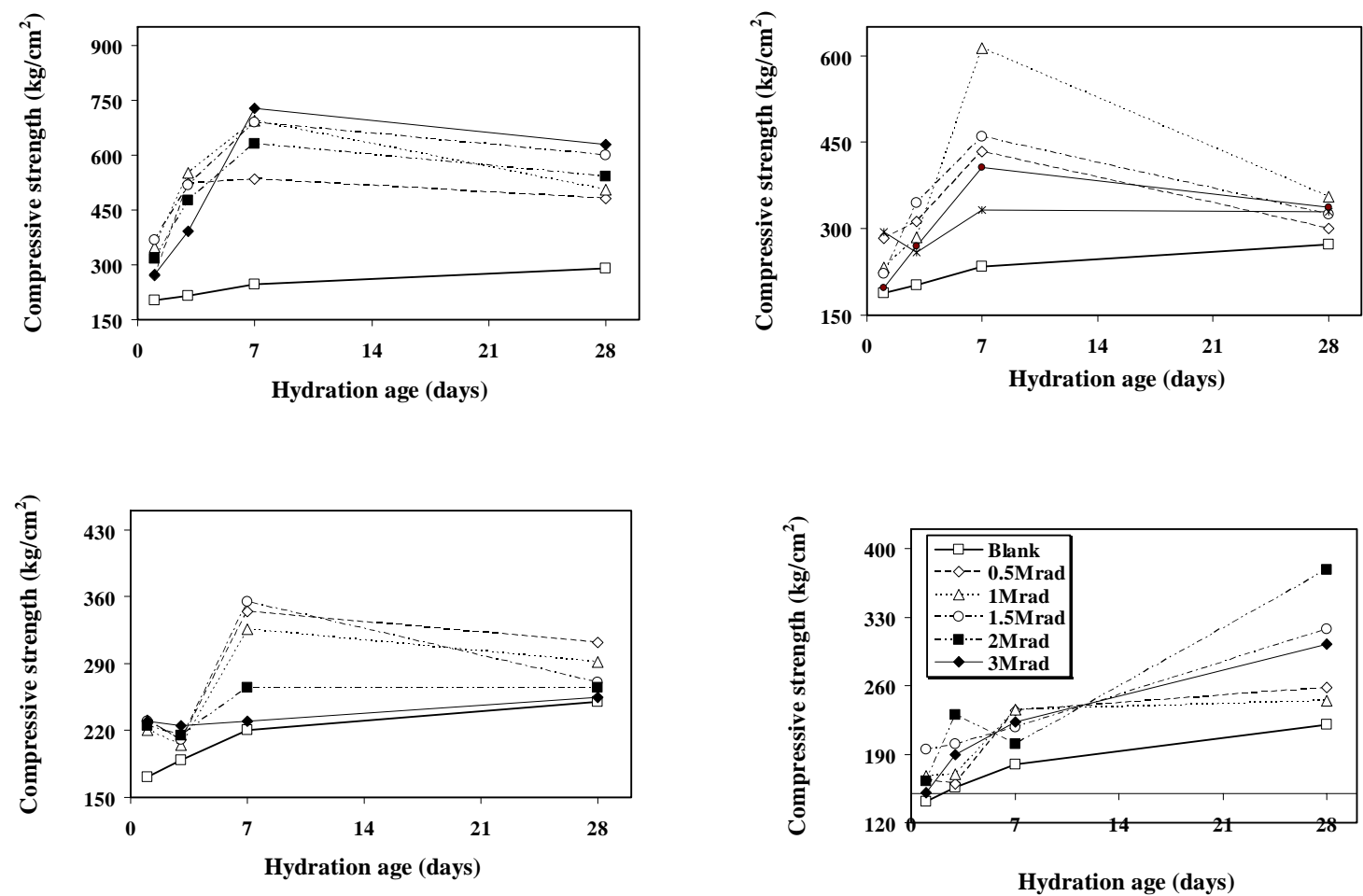

Fig.(2): Compressive strength $(\mathrm{kg} / \mathrm{cm} 2)$ of the hardened OPC mortar pastes impregnated with polyurethane (C.O. + MDI) at different doses of $\mathrm{Y}$ - radiation as a function of the hydration age, (W/C ratios $0.25,0.30,0.40$ and 0.50$)$. 

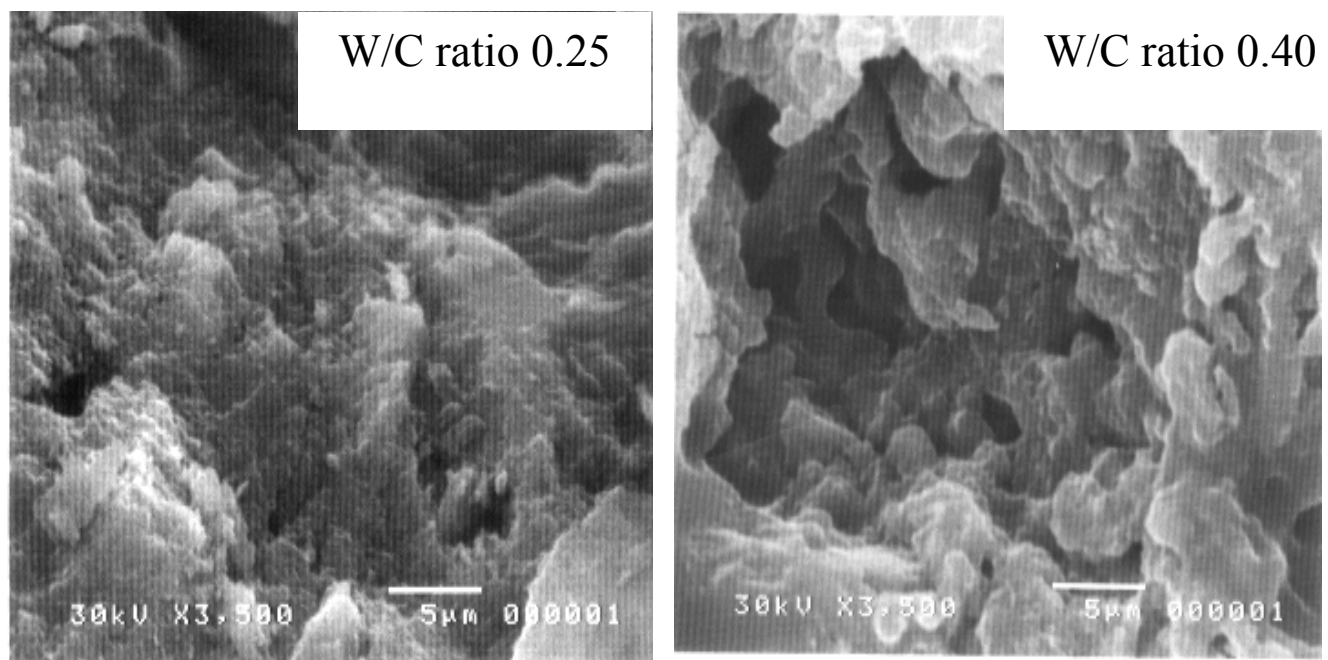

Fig. (3): SEM micrographs of the hardened cement mortar pastes made of OPC impregnated with polyurethane ( $\mathrm{MDI}+\mathrm{C} . \mathrm{O}$.) , (W/C ratio $0.25 \& 0.40)$, hydration time 28 days.
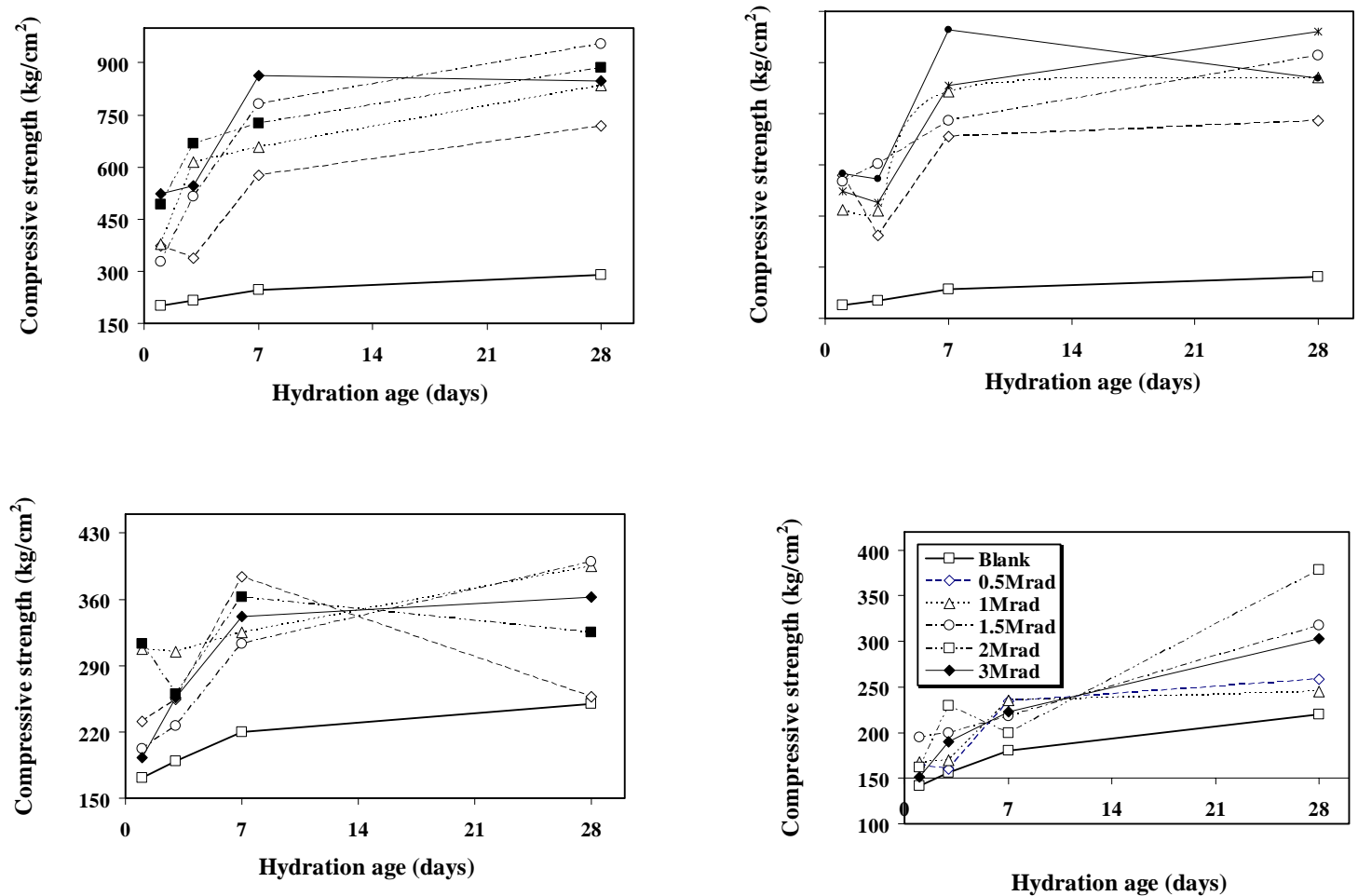

Fig.(4): Compressive strength $\left(\mathrm{kg} / \mathrm{cm}^{2}\right)$ of the hardened OPC mortar pastes impregnated with polyurethane (C.O. + MDI) - MMA copolymer at different doses of $\mathrm{Y}$-rays as a function of the hydration age, (W/C ratios $0.25,0.30,0.40$ and 0.50 ). 

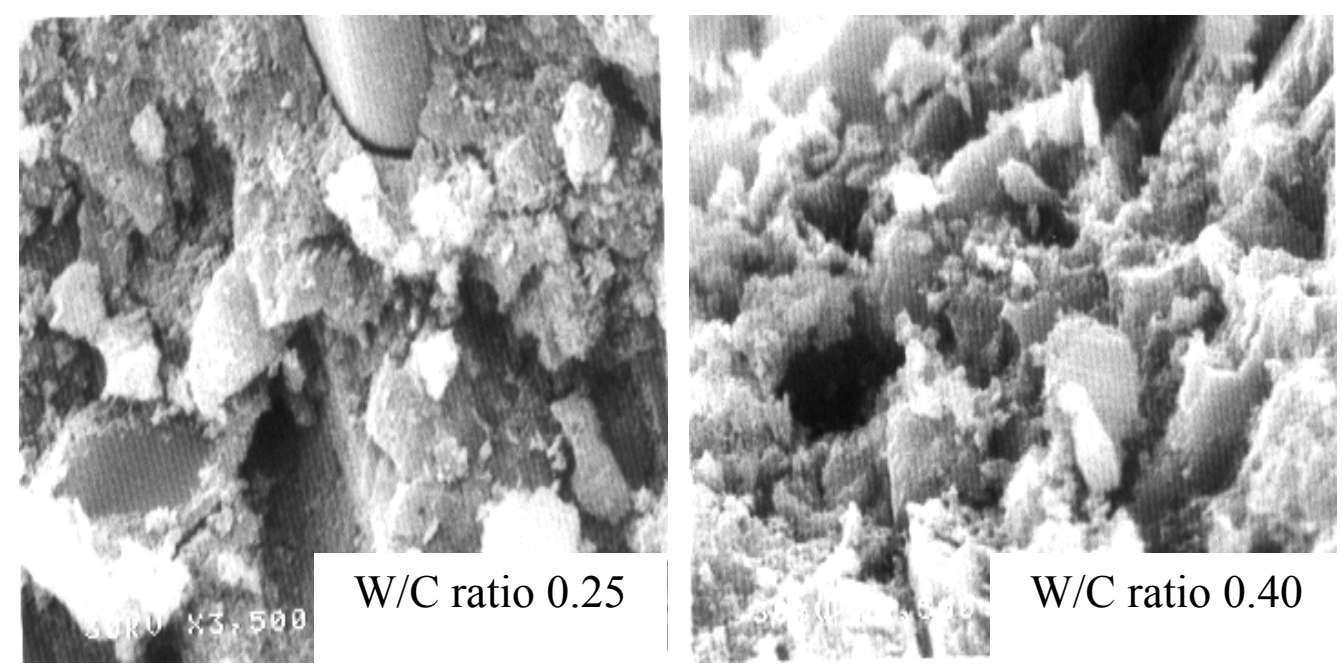

Fig. (5): SEM micrographs of the hardened cement mortar pastes made of OPC impregnated polyurethane (C.O. + MDI) - MMA copolymer, (W/C ratio $0.25 \& 0.40)$, Hydration time 28 days. 